\title{
Investigating Mathematics Anxiety over Time in University Engineering Students
}

\author{
Kimberly M. Levere and Parveen Kaur Kahlon \\ University of Guelph \\ 50 Stone Road E., Guelph, Canada N1G 2W1
}

\begin{abstract}
In this paper we investigate the presence of math anxiety (MA) among University Engineering students at all levels of undergraduate study. In an effort to assess the presence and severity of MA over the course of an undergraduate degree, as well as to quantify the number of highly math anxious students in this STEM discipline, a 29-question survey was conducted in each of five levels of undergraduate Engineering students. Using non-parametric statistical methods such as Kruskal-Wallis and Mann-Whitney tests as well as pairwise proportion comparisons, MA was compared across years of study. Utilizing existing anxiety classifications of Math Evaluation Anxiety (MEA), Learning Mathematics Anxiety (LMA) and Numerical Anxiety (NA), it was found that MEA showed the highest anxiety scores, while LMA and NA remained at or below a neutral anxiety score in all years of study. MEA questions related to anticipation of evaluation and the receipt of grades revealed the highest scores and the greatest discrepancy in anxiety by year (with Year 1 students more highly anxiously than later years in nearly all cases). Although earlier research suggests that MA tapers off by grade 10, this research suggests that while first-year university students exhibit low levels of LMA and NA, they continue to exhibit high levels of MEA. This result may be in part due to the level of questions on traditional MA assessment questionnaires addressing lower level mathematical concepts (such as addition, subtraction, multiplication and division). Since students gain comfort and mastery of concepts as they use them more frequently, this study suggests that such metrics for MA must be adjusted in order to accurately assess students as they progress through later years of study.
\end{abstract}

Keywords: mathematics anxiety; STEM; post-secondary; assessment; over time.

\section{Introduction and Past Research}

Mathematics anxiety (MA) defined by Richarson \& Suinn (1972) as "a feeling of tension, apprehension, or fear that interferes with math performance" has become increasingly prominent in students at all levels of study. As Ashcraft 
and Moore (2009) note, not all students experience MA to the same degree; some experience frustration, others report more severe emotional impacts both on cognitive and physiological scales (Faust, 1992).

The prevalence and variation in MA severity suggest the need for a metric for measuring the presence and perhaps the severity of MA in a student. Several scales and assessments have been constructed for diagnosing and identifying MA, beginning with the Taylor Manifest Anxiety Scale (TMAS) (Taylor, 1953) which assesses anxiety more generally (not specifically MA) (O'Connor et al., 1956). Shortly thereafter, Dreger and Aiken (1957) added three MA questions to the TMAS in an effort to produce a standardized assessment more specific to identifying MA. They discovered that so-called "Number Anxiety" (emotional reactions to arithmetic and mathematics) is separate from general anxiety and does not appear to be related to one's general intelligence. However, those with high Number Anxiety indeed seem to achieve lower scores in mathematics. Many years later, Richardson and Suinn (1972) produced what remains a standard MA scale even today, the Mathematics Anxiety Rating Scale (MARS). These 98 questions on a 5-point Likert-scale give respondents the opportunity to indicate the level of anxiety that they experience in both everyday mathematical tasks as well as educational situations. While this scale has been used in many publications since its inception, its length is often seen as a limitation. For this reason, a number of adaptations have been made to the original scale to target its original length and efficiency, for instance via a revised version, the MARS-R by Plake and Parker (1982), and abbreviated versions, the AMARS by Alexander and Martray 1989), and the AMAS by Hopko et. al. (2003). Other versions such as the MARS-A targeted MA in adolescent groups.

In addition to effective measures for identifying MA, a great deal of research has focussed on the causes, effects and trends of MA. For instance, in a study by Turner et. al. (2002), teacher expectations were investigated. It was conjectured that if a teacher has a high demand for correctness but provides little support that this can promote the development of MA in students. In a similar vein, Beilock et. al. (2010) investigated the possibility that the level of math anxiety that the teacher possesses can contribute to a negative stereotype toward mathematics in students. In this study, teachers were female, and results showed that female students attained lower math achievement than their male counterparts.

A series of particularly compelling studies investigated the idea that people perform worse on mathematical assessments than their abilities suggest that they should (Ashcraft \& Faust, 1994; Ashcraft \& Kirk, 2001). When comparing performance using standard computerized laboratory tasks versus pencil-andpaper formatting (the latter of which was designed to reduce anxiety), it was found that the competency of low and highly math-anxious people is approximately equal, while in the higher pressure circumstance, the performance of highly math-anxious people seems to fall below this expectation. To explain this phenomenon, it was proposed that the negative thoughts and feelings that people feel toward mathematical tasks (and the effort expended 
attending to these thoughts and feelings) indeed distract resources from working memory. Simplistic questions that do not require working memory (such as basic addition of single-digit numbers), will not be affected by such a phenomenon, while more involved tasks (like addition of two-digit numbers requiring carrying; a two-fold task) indeed will be more challenging for those operating with a reduced working memory and thus can flag MA. An experiment was conducted involving the completion of "basic", "medium" or "large" mathematical problems under "high" (remembering a sequence of 6 letters) or "low" (remembering a sequence of 2 letters) verbal memory loads. Following the mathematical task, subjects were asked to recall, in order, their sequence of letters. As expected, when recalling a sequence following a "large" mathematical problem involving more complex calculations a greater number of errors were seen for highly math-anxious subjects as compared to low mathanxious subjects. Despite having equal capacity working memories in the absence of mathematical content, it was observed that indeed being subjected to mathematical content reduced the working memory capacity of highly mathanxious individuals.

While it is unclear when the onset of MA begins, or if this is different for everyone or based on circumstance, Hembree (1990) suggests that MA peaks at Grade 9 of 10 and levels off thereafter. This study and another by Choe et. al. (2019) also suggest that once a student identifies as having MA they frequently have negative feelings toward mathematics which can cause an avoidance of mathematical courses. In a similar study by Fennema (1989), highly mathanxious students spend less time on the few mathematics courses that they do enrol in and avoid degrees and careers in math-focussed disciplines. Ahmed (2018) completed a study that followed a cohort of grade 7 and grade 10 students beyond their high school studies. Respondents were given questionnaires and achievement tests in math and science in 1987. Thirty years later, in 2007, 95\% of these respondents were located and asked to complete a survey regarding their education and occupations. With a $78 \%$ response rate on this survey, it was concluded that those that had "consistently low" MA were 7.4 times more likely to land in STEM-related occupations than those that had "consistently high" MA. Beyond this study, it seems that studies of MA over time are limited to students at grade 6 or 7 level (Ahmed et. al., 2013; Madjar et. al., 2018) or those transitioning to junior high school (Wigfield \& Eccles, 1989). Collectively these studies suggest a potential decrease in MA from grade 6 to 7 , but otherwise little to no noticeable change within a two-year period.

In this paper, we investigate further the idea of MA over time. Recognizing the detrimental effect that MA has on STEM disciplines and occupations in STEM, we explore MA in Engineering students at the University of Guelph in each year of study.

\section{Background}

An Engineering degree at the University of Guelph can be completed in one of seven programs, Biological, Biomedical, Computer, Engineering Systems \& Computing, Environmental, Mechanical, or Water Resource Engineering. A 
degree in Engineering traditionally takes 4 years to complete, (except for students enrolled in the cooperative education program which takes 5 years to complete in total). Regardless of what program a student is registered in (in fact, a student can enter the program as "undeclared" and later choose a specific program), all students are required to take the same set of mathematics courses. Traditionally taken in the first year, all students take MATH*1200 - Calculus I, MATH $^{*} 1210$ - Calculus II, and ENGG*1500 - Engineering Analysis (a course in Linear Algebra). Traditionally taken in the second year of study, all students are required to take STAT*2120 - Probability and Statistics for Engineers,

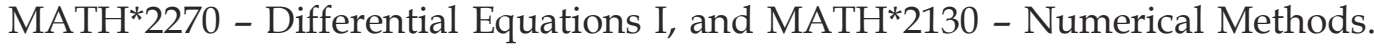
Following these core courses, the different programs vary in the additional mathematical content that they study. For instance, Mechanical Engineering students are required to take a more mathematically intensive set of courses in the remainder of their degrees than, for instance, Environmental Engineering students purely based on the applications and toolset that these programs require.

There are three entry-level Calculus courses offered at the University of Guelph depending on the area of study. MATH*1200 - Calculus I is intended for students who intend to pursue further studies in mathematics throughout their degrees. This course, unlike others at entry-level, explores not only the ability of students to complete complex calculations but also introduces them to pure mathematics and techniques of proof. MATH*1210 - Calculus II follows in a similar vein, but studies concepts beyond a traditional high school curriculum. Each of the 6 required mathematics credits for an Engineering degree are offered in one semester per year (with the exception of STAT*2120 which is offered in both Fall and Winter semesters yearly). Since most of these courses are prerequisites for later courses, it is the case that if a student is not successful in one of these courses that they are indeed held back by nearly a year when it comes to their core Engineering courses. This combined with heavy course loads (depending on the program, some students may be enrolled in as many as six courses all with demanding lecture and lab schedules) makes Engineering a challenging degree program within the STEM disciplines. Due to the presence and consistency of mathematical exposure in this degree program, as well as how much it relies on mathematical constructs, it was chosen for this investigation.

\section{Outline of Study}

The objectives of this study are two-fold. Firstly, to analyse the presence (or absence) of MA in a STEM discipline (in this case, Engineering) at the postsecondary level and estimate the proportion of highly math anxious students in this degree. Secondly, to investigate how (if at all) MA changes over the years of study of an Engineering undergraduate degree. As an additional point of interest, student perception of MA over time will be investigated.

\subsection{Participants}

In order to carry out this research, Research Ethics Board Approval was attained for administering a 29-question survey regarding student reactions and opinions 
toward mathematics and MA. Much like the original MARS, all questions on the survey used in this study sought responses on a 5-point Likert scale, where students indicated their level of anxiety for each situation as either 1 for "none at all", 2 for "a little", 3 for "a moderate amount", 4 for "a lot", and 5 for "a great deal". A 29-question survey (whose questions are listed in the Appendix at the end of this paper) was constructed using Qualtrics ${ }^{X M}$ online survey software. This software is well-known and allows the researcher the ability to tailor and refine its settings to meet their needs. In order to ensure that only Engineering students were polled and that a wide variety of years of study were covered, specific core, required Engineering courses were selected to take this survey. The Year 1 cohort was gathered from an Engineering Mechanics I (ENGG*1210) course; a math intensive, core course for all entry-level Engineering students. This course is traditionally one of the more challenging courses in the first-year curriculum due to a heavy focus on problem-solving, the difficulty of problems explored, and a high quantity of content. The Year 2 cohort was captured by surveying students in Fluid Mechanics (ENGG*2230), a course that takes previous mathematical concepts covered in first-year studies and extends them to explore more complex fluid flow problems. The Year 3 cohort was captured by surveying students in Heat and Mass Transfer (ENGG*3430), again, a mathintensive core course for all Engineering students that explores and extends earlier mathematical concepts. Finally, the Year 4 and Year $4+$ cohorts were captured by surveying those in a capstone Design course (ENGG*4100). Engineering students take at least one design course per year with this final design course acting as a culmination of all of their studies and efforts throughout their degrees. They work in small groups to develop and design prototypes or ideas that improve or advance a particular area of Engineering study. Certainly, students in the cooperative education program take these courses off-stream, so it is possible to have collected data from different years of study in each course. However, as each course is a prerequisite for the next one surveyed it was not possible that a student could be surveyed multiple times. The survey was entirely anonymous, and all users were asked for their consent to participate or were given the option not to. They were also instructed that they could leave questions unanswered at any time or quit at any time during the survey and that incomplete surveys would not be used in our results. A total number of 338 responses were obtained from all engineering students surveyed over the period from March 17, 2019 to April 25, 2019. Specifically, from year 1, $2,3,4$, and $4+$ there were $70,111,43,64$, and 50 , respondents, respectively. It is of interest, perhaps, to note that the time period over which this was completed began in week 10 of a 12-week semester and included responses in weeks 10, 11, and 12 as well as during both weeks of exams.

\subsection{Structure of the Survey}

The questions chosen for the survey used in this study were both existing MARS questions (or slight modifications), or questions that were deemed of interest for the university-level respondents (such as questions regarding more difficult mathematical constructs, or their applications). Within the literature, different sources identify a variety of factors associated with MA. As a result, the questions chosen for this survey sought to incorporate three such factors 
associated with MA. Rounds and Hendel (1980) identified two of these factors using the original MARS survey and factor loading scores. The first is Numerical Anxiety (NA), identified as everyday situations requiring some form of number manipulation, or elementary and practical arithmetic skills.

Question 24 of the survey used in this study combines a few of the questions on the original MARS (regarding the basic operations of addition, subtraction, multiplication, and division), but is in spirit capturing the same information.

Questions 25 and 26 are similar in nature but extend to higher level functions studied in the later years of high school and in university, namely logarithmic, exponential, and trigonometric functions. As students do not spend as much time with these functions in secondary school, they are often seen as more challenging by students (challenges with these higher-level functions is explored in Levere \& Demers, 2017). As university level students use much more than the basic operations of mathematics, it was decided that aspects of extension of concepts and life-long learning be incorporated into the survey in this category.

To this end, Question 27 regarding extensions of problems done in class and Question 28 regarding the use of material taught in a previous course have both been added to the NA category. The second factor identified by Rounds and Hendel is Mathematical Test (or Evaluation) Anxiety (MEA) which is defined as an apprehension about, or an anticipation of, taking, and/or receiving the results of a mathematics test. MEA may also refer to activities that are directly associated with mathematics courses. MEA has been identified by many researchers as a key factor in MA (see for instance, Alexander \& Martray, 1989 and Plake \& Parker, 1992).

Questions 7-14 in the survey used for this study were also used in the original MARS study. Some minor adjustments were made to ensure consistency with University of Guelph workflow. For instance, in Question 10, since grades are released via an online website called "Webadvisor" and not through the mail (as the original MARS question lists), this change was made. Question 23 regarding waiting outside of a classroom before a test is to begin was also added under this category. The third factor considered in this work was offered by Plake and Parker (1992) when investigating a revision that shorted the original MARS scale to 24 items. While they too identified MEA as a factor, they suggested that Learning Mathematics Anxiety (LMA) was also an important factor. They define LMA as an activity related to learning mathematics such as classroom activities, lectures/lessons, the physical act of walking to a mathematics class, or signing up for a mathematics class. LMA also includes studying mathematics, looking through a mathematics textbook, utilizing charts or tables, and/or buying a mathematics textbook.

Questions 15-21 in the survey used for this study all appear on the original MARS and have been identified in other studies as LMA indicators. Question 22 which asks about a student explaining a math formula right before a test (a modification of an existing question on the MARS) was also added in the LMA 
category. Question 29 asks about seeking the help of the professor in office hours (a modification of an existing MARS question).

Finally, Questions 1 and 2 were used for classification of grade and program, while Questions 3-5 sought information regarding student perceptions of math content present in their courses and their opinions on preparation for the workforce. Question 6 was added to capture student perception of changes in MA over time, relative to their MA level in the previous year.

\section{Results}

As the responses for each question were collected on a Likert scale, traditional parametric statistics were deemed unsuitable. Instead, since our data is based on ordinal data, we look to a non-parametric test (that is, one that does not require any assumptions on the distribution of our data) for our analysis. In our case, we wish to compare the distribution of each year of study and thus, we will use a Kruskal-Wallis test (sometimes called the non-parametric equivalent to the oneway ANOVA). Using medians (rather than means as parametric tests often do), the Kruskal-Wallis test assesses if population medians of all groups are equal. Should equality be rejected, it is of interest to determine where the difference(s) occur. Much like a Fisher Least Significant Difference comparison for parametric tests, here we will utilize a Mann-Whitney test to do a pairwise comparison of each possible pairing (this is similar to a t-test for equality of means for parametric data). All Kruskal-Wallis tests were done at the $\alpha=0.05$ level of significance, while pairwise comparisons done via Mann-Whitney tests utilized a Dunn-Sidak correction which distributes the level of significance over the family of comparisons being run. As there were 10 pairwise comparisons considered for each question, the level of significance used was $1-(1-\alpha)^{\frac{1}{10}} \simeq$ 0.005116 for each Mann-Whitney test. Finally, an assessment of the proportion of highly anxious students across their year of study was conducted using pairwise proportions. Once again a Dunn-Sidak correction was used to distribute the level of significance of $5 \%$.

Firstly, each individual question was investigated with groups represented as years of study. Not only is it important to investigate a difference between years of study, but also the relative scores between years; just because there is a significant difference in anxiety between years does not immediately mean that that event causes high MA. Below we explore each category of MA in turn.

\subsection{MEA Results}

Table 1 below lists the questions that were found to be significant different across year of study in the MEA category together with the p-value of the Kruskal-Wallis test and mean scores across year of study. For brevity, in this and all other sections, individual results of pairwise Mann-Whitney tests are not listed here, but are referred to in the discussion. 
Table 1. Average scores across years of study for MEA questions together with p-value achieved when testing for a difference in median scores between years of study via Kruskal-Wallis.

\begin{tabular}{|c|c|c|c|c|c|c|c|}
\hline \multirow[b]{2}{*}{ Question } & \multirow[b]{2}{*}{ Description } & \multicolumn{5}{|c|}{ Average Score } & \multirow[b]{2}{*}{ p-value } \\
\hline & & $\begin{array}{c}\text { Year } \\
1\end{array}$ & $\begin{array}{c}\text { Year } \\
2\end{array}$ & $\begin{array}{c}\text { Year } \\
3\end{array}$ & $\begin{array}{c}\text { Year } \\
4\end{array}$ & $\begin{array}{c}\text { Year } \\
4+\end{array}$ & \\
\hline 7 & $\begin{array}{l}\text { Difficult problems } \\
\text { due next class }\end{array}$ & 2.96 & 2.74 & 2.79 & 2.75 & 2.54 & 0.391882 \\
\hline 8 & $\begin{array}{l}\text { Thinking about a } \\
\text { test } 1 \text { day before }\end{array}$ & 3.99 & 3.54 & 3.37 & 3.27 & 2.92 & 0.0000526 \\
\hline 9 & Taking a quiz & 2.84 & 2.68 & 2.74 & 2.73 & 2.32 & 0.034513 \\
\hline 10 & $\begin{array}{l}\text { Grade on Web } \\
\text { Advisor }\end{array}$ & 3.86 & 3.48 & 3.53 & 3.34 & 2.84 & 0.00305 \\
\hline 11 & $\begin{array}{l}\text { "pop" iClicker } \\
\text { quizzes }\end{array}$ & 3.13 & 2.78 & 2.95 & 2.86 & 2.7 & 0.337439 \\
\hline 12 & $\begin{array}{l}\text { Waiting for } \\
\text { midterm return - } \\
\text { expect to do well }\end{array}$ & 2.94 & 2.78 & 2.79 & 3.03 & 2.16 & 0.001202 \\
\hline 13 & $\begin{array}{l}\text { Waiting for } \\
\text { midterm return - } \\
\text { expect to do poorly }\end{array}$ & 4.29 & 3.72 & 3.63 & 3.94 & 3.14 & 0.0000283 \\
\hline 14 & Final exam & 4.19 & 3.6 & 3.58 & 3.47 & 3.1 & 0.0000354 \\
\hline 23 & $\begin{array}{l}\text { Waiting outside a } \\
\text { classroom to write a } \\
\text { test }\end{array}$ & 3.93 & 3.38 & 3.37 & 3.53 & 2.82 & 0.000257 \\
\hline
\end{tabular}

Table 1 reveals a few interesting trends. In all but one instance, Year 1 students represent the highest anxiety in each of these questions, although not all questions indicate high anxiety. For instance, in Question 9 regarding taking a quiz, Year 4+ students were found to have a significantly lower median anxiety score than Year 1 students (all other pairwise comparisons were insignificant, statistically). Despite this difference, we see that average scores across all years of study are below a neutral score of 3. Question 11 regarding in-class pop quizzes was not found to be significant across year of study but did show a similarly neutral to low MA score across all years as did Question 7 (also not significantly different across year of study) regarding doing difficult problems that are due the next class. In both questions, scores are at a level 2 on the anxiety scale ("a little") with the exception of Year 1 respondents who creep just above neutral regarding anxiety for in-class pop quizzes via i-Clicker. One characteristic that these questions have in common is that the weight that they carry toward a student's final grade is relatively low. If fear of failure is a driver for anxiety (there is a plethora of literature in this area, see for instance, Alpert \& Haber, 1960), these assessments may be seen as not enough to "make or break" a student in a course (see Nathan, 2005 for a study on student motivation). Further, these assessments often cover a small amount of material making it easier to master the concepts being tested. In the case of Question 7, students will often work in groups with their peers and therefore do not feel quite the onus to perform individually should they be struggling. 
Assessments that carry a larger weight (and therefore can have a greater impact on student success or failure in a course) are those that seem to reveal higher MA scores in our survey. To this point, we observe that Question 14 regarding writing a final exam in a math course produces average scores that are all at or above neutral with Year 1 students in the "a lot" category for MA. Further, pairwise comparisons indicate that Year 1 students report higher anxiety than Year 4 and Year 4+ students. Noting that exams are often a more expensive (if not the most expensive) assessment in a course, we see that it induces more MA than the smaller quizzes discussed in Question 9 and 11. Because final exams carry so much weight, they can have a major impact on a student's success. If they do not perform on this assessment, it is likely that their grade will suffer considerably. This pressure and the fear of failure seem to be major drivers of MA This is echoed again in Question 10 regarding students receiving their final course grades on Web Advisor. While average scores remain in the neutral category (with Year 4+ students just below), indeed, pairwise comparisons reveal higher anxiety in Year 1 students as compared to Year 4+ students. Perhaps the results indicate that students desensitize in time to these worries, or perhaps they have learned how to prepare for these larger assessments in different ways over time so that they are more confident in their ability to succeed (see for instance, an article by McGhie, 2017 regarding challenges with transition to university for further insight). One might argue that students in Year 4 or $4+$ are preparing to graduate and thus they may place less importance on the quality of grade they receive provided that they pass. They may also be more confident because they are so close to finishing their degree. On the contrary, younger students may not yet believe in their abilities and they may care more about the numeric grade they receive because of scholarship renewal requirements, for instance (see studies by Immerwahr, 2011, and McKeachie, 1999 on confidence and grade motivation). In the transition from secondary to post-secondary, some students have not yet adjusted to the university environment. Younger students may be more focussed on their marks as the result of the mark-centric nature of secondary school; students are vying for acceptance at top post-secondary institutions which (almost exclusively) use grades as a measure for acceptance. Finally, Question 8 regarding thinking about a math test that is to occur the next day showed a significantly higher level of anxiety in Year 1 students than in all other years of study (except for Year 2). Although slightly less than the average MA scores in the final exam category, Year 1 students are very nearly at an average score of "a lot", while all other years decrease monotonically to Year $4+$ which falls just below neutral. The idea that strong performance is required on a short timeline may produce anxiety as students may be ill-prepared with little time to improve and feel unconfident in their ability. Time management is a major challenge, particularly in the early years of university studies (see, for instance, Nathan, 2005). This could be a reason why Year 1 students in pairwise comparisons are more anxious than all other years.

Question 8 recognizes another trend in our data; anticipation. Not only does a test carry significant weight toward a student's final grade, but this question also embeds the anticipation of a test that is to happen in the near future. We made 
mention of time management and struggling to find time to study effectively as reasons why such anticipation may cause anxiety, but perhaps the act of waiting plays a role in anxiety as well (see Grupe \& Nitschke, 2013 for a study regarding anticipation and anxiety). Running through scenarios in one's mind and worrying about what one is and is not prepared for are also reasons why anticipation may be a major factor in anxiety. In Question 12 regarding waiting for the return of a midterm on which a student expects to do well, while significant (once again, Year 4+ exhibited lower median scores as compared to nearly every other year in pairwise comparisons) again produces scores that are all below (or at) a neutral level of anxiety. Conversely, in Question 13 regarding students waiting for the return of a midterm when they expect to do poorly, we see a vast increase in average scores. Suddenly, scores hover closer to or even above (in the case of Year 1 students) "a lot" of anxiety with not a single year falling below the neutral anxiety score. Interestingly, pairwise comparisons within Question 13 show that Year 1 students have significantly higher scores than nearly every other year on this question (in addition, Year 4 is significantly higher than Year 4+). In fact, this question represents the highest average MA scores of any question in this category across years. This pairing of questions further supports the idea that anxiety and fear of failure go hand in hand. The much higher anxiety scores when students expect that they have done poorly are indicative of this. Question 23 involving the act of waiting outside of a classroom just before a test is to begin also incorporates anticipation. Surrounded by a group of one's peers and listening to others discussing questions and topics that are imminently to be tested is an environment that seems to be wrought with anxiety and tension. Indeed, the numbers agree: all but Year 4+ students have average scores between neutral MA and "a lot". Once again, there is a significantly higher median anxiety score in Year 1 students as compared to Year $4+$ students. Similar explanations apply here; a lack of experience and discomfort with surroundings together with the worry of "tarnishing" a strong high school average may make this environment more anxious for Year 1 students. Fear of failure, or perhaps even competitiveness with their peers are all reasons why this environment remains an anxious one throughout all years of study. Class size may also play a part in higher anxiety in earlier years of study; being surrounded by a very large crowd (500-600 students) versus smaller groups in later years (40-50) could have a major impact on the level of anxiety felt in this circumstance.

When looking at the proportion of "highly anxious" (HA) students in each year, within the MEA category, the proportion of HA students ranged from $18 \%$ in Year 4+ students to almost $41 \%$ in Year 1 students (note that the increase was not monotonic among years). MEA was found to produce a significantly higher proportion of HA students in Year 1 than in Year 4+. As HA was not welldefined in the literature, we conservatively evaluated a student as HA in MEA if out of the 9 questions in this category they scored a level 4 or 5 on the anxiety scale in at least 6 questions. 


\subsection{LMA Results}

Table 2 below lists the questions that were found to be significant different across year of study in the LMA category together with the p-value of the Kruskal-Wallis test and mean scores across year of study.

Of the 9 questions in the LMA category, only 4 of them indicated a significant difference in anxiety between years of study. Notice that as a whole, anxiety scores on these questions are rather low. In all but one question, average scores never exceeded the level 2 anxiety rating of "a little", with many scores even within the level 1 rating of "none at all". This would indicate that students are not feeling as much MA when it comes to the act of learning mathematics. The single question that showed a slight elevation in anxiety score (although still within the neutral level) was Question 22 regarding listening to another student explaining a math concept right before a test. This question was nearly identical to Question 21 regarding listening to another student explaining a math concept but this time while doing homework problems. When the environment is more relaxed (doing homework rather than just before a test), the anxiety scores drop nearly a whole level, question-to-question, to level 2, "a little" or even level 1 "none at all". There was not a significant difference between years of study on Question 21, while the related Question 22 (just before a test) showed a significantly higher median anxiety score in Year 1 students compared to Year $4+$ students. Certainly, there is an element of test anxiety imposed in this question which may be a reason for the higher anxiety rating. The anticipation of testing may also be a factor. One might argue that if a student is worried that they may not be prepared for the imminent test that knowing that others are prepared may make them feel even more inadequate. Further, trying to learn a concept "just in time" for an assessment puts pressure on a student to understand quickly without time to practice or feel comfortable in their ability. In contrast, working with peers to understand the material in a more relaxed setting (while doing homework) the pressure is reduced. Students are less likely to feel inadequate because they are still learning; an environment where it is more acceptable to be unsure of a concept and seeking help when a test is not looming.

Table 2. Average scores across years of study for LMA questions together with p-value achieved when testing for a difference in median scores between years of study via Kruskal-Wallis.

\begin{tabular}{|c|c|c|c|c|c|c|c|}
\hline & & & & verage & Score & & \\
\hline Question & Description & $\begin{array}{c}\text { Year } \\
1\end{array}$ & $\begin{array}{c}\text { Year } \\
2\end{array}$ & $\begin{array}{c}\text { Year } \\
3\end{array}$ & $\begin{array}{c}\text { Year } \\
4\end{array}$ & Year 4+ & p-value \\
\hline 15 & Abstract math problem & 2.87 & 2.23 & 2.37 & 2.08 & 1.76 & 0.00000118 \\
\hline 16 & $\begin{array}{l}\text { Picking up a textbook to do } \\
\text { homework problems }\end{array}$ & 2.1 & 1.95 & 1.84 & 1.86 & 1.58 & 0.039659 \\
\hline 17 & $\begin{array}{l}\text { Opening up a textbook to } \\
\text { see a full page of problems }\end{array}$ & 2.29 & 2.23 & 2.07 & 2.08 & 1.8 & 0.074224 \\
\hline 18 & $\begin{array}{l}\text { Walking on campus } \\
\text { thinking about a math } \\
\text { course }\end{array}$ & 2.34 & 1.90 & 1.72 & 1.80 & 1.48 & 0.000182 \\
\hline 19 & Graphs and charts & 1.91 & 1.72 & 1.88 & 1.77 & 1.54 & 0.098801 \\
\hline
\end{tabular}




\begin{tabular}{|c|l|l|l|l|l|l|l|}
\hline 20 & Using tables & 1.67 & 1.66 & 1.77 & 1.66 & 1.36 & 0.119154 \\
\hline 21 & $\begin{array}{l}\text { Another student explaining } \\
\text { a question when doing } \\
\text { homework }\end{array}$ & 2.31 & 1.99 & 2.14 & 2.08 & 1.92 & 0.257136 \\
\hline 22 & $\begin{array}{l}\text { Another student explaining } \\
\text { a question right before a } \\
\text { test }\end{array}$ & 3.64 & 3.37 & 3.47 & 3.45 & 2.88 & 0.041921 \\
\hline 29 & $\begin{array}{l}\text { Visiting a professor to ask } \\
\text { for help }\end{array}$ & 2.3 & 2.31 & 2.72 & 2.28 & 1.96 & 0.052898 \\
\hline
\end{tabular}

Three questions in this category produced level 2 ("a little") anxiety at all years of study except Year 4+ which was at a level 1 ("none at all"). Question 17 regarding opening a textbook full of problems did not exhibit a significant difference over years of study, and neither did Question 29 regarding seeking help from the professor. Question 15 regarding working on abstract math problems produced significantly higher median scores in Year 1 students as compared to almost all other years. Year 3 was also significantly higher than Year 4+. This is likely due to a lack of confidence either in the material itself, or in the student's ability. The word "abstract" in this question may also have encouraged slightly higher anxiety scores. The idea that a question is abstract and perhaps not straightforward may cause students to worry about their ability to figure it out. In time, students do gain better insight into and more familiarity with these sorts of problems and tend to have more confidence in their ability and overall knowledge. This perhaps explains why Year 1 students exhibited higher median anxiety scores compared to later year students.

The remaining questions produced primarily scores that fell in the "none at all" anxiety rating nearly across the spectrum of years of study. The exception was with Year 1 students, although their average scores were very slightly above a level 2 of "a little". Question 16 regarding opening a textbook to do homework problems revealed a significantly higher median score in Year 1 students versus Year $4+$ students. This again could be explained by a student's lack of confidence or fear of failure. Finally Question 18 regarding walking on campus thinking about a math class produced significantly higher median scores in Year 1 students than nearly every other grade. Even still, these scores are still at most a level 2 ("a little"). Finally, Questions 19 and 20 revealed a lack of anxiety across all years associated with reading graphs, tables and charts. This lends truth to the idea that as students spend more time with a concept, they become more comfortable with it and experience less anxiety (see Jansen et. al., 2013 for instance).

When considering the proportion of HA students in the LMA category, proportions were much lower than that of MEA; from $0 \%$ in Year $4+$ to just under $5 \%$ in Year 3 (again, proportions were not monotonic between years of study). None of the pairwise proportions between years produced a significant difference in the proportion of HA students. This result is consistent with others found in this study regarding LMA. For the LMA category, HA was classified as a student scoring a 4 or 5 on the anxiety scale in at least 6 of the 9 questions. 


\subsection{NA Results}

Table 3 below lists the questions that were found to be significant different across year of study in the NA category together with the p-value of the Kruskal-Wallis test and mean scores across year of study.

Table 3. Average scores across years of study for NA questions together with p-value achieved when testing for a difference in median scores between years of study via Kruskal-Wallis.

\begin{tabular}{|c|c|c|c|c|c|c|c|}
\hline & & \multicolumn{5}{|c|}{ Average Score } & \multirow[b]{2}{*}{ p-value } \\
\hline Question & Description & $\begin{array}{c}\text { Year } \\
1\end{array}$ & $\begin{array}{c}\text { Year } \\
2\end{array}$ & $\begin{array}{c}\text { Year } \\
3\end{array}$ & $\begin{array}{c}\text { Year } \\
4\end{array}$ & $\begin{array}{c}\text { Year } \\
4+\end{array}$ & \\
\hline 24 & $\begin{array}{l}\text { Add/subtract } \\
\text { Multiply/divide }\end{array}$ & 1.76 & 1.50 & 1.42 & 1.55 & 1.18 & 0.018358 \\
\hline 25 & $\begin{array}{l}\text { Logarithms/Exponen } \\
\text { tials }\end{array}$ & 2.6 & 2.18 & 2.21 & 1.98 & 1.84 & 0.002971 \\
\hline 26 & Trigonometry & 2.83 & 2.20 & 2.23 & 2.02 & 1.76 & 0.00000118 \\
\hline 27 & Extension questions & 2.9 & 2.83 & 2.58 & 2.56 & 2.54 & 0.106329 \\
\hline 28 & $\begin{array}{l}\text { Using material from } \\
\text { previous courses }\end{array}$ & 3.14 & 2.67 & 2.65 & 2.81 & 2.68 & 0.052898 \\
\hline
\end{tabular}

Looking at the average scores across years of study, we see that much like many of the LMA results, NA results produce relatively low average anxiety scores. Only a single score even reaches a neutral level of anxiety; Year 1 students when asked about the use of material from other courses. However, the differences between years for this question were not significant. Similarly, in Question 27 regarding extension questions we see a slight elevation in scores (although all remain, on average at a level 2 on the anxiety scale), but again, not a significant difference between years of study. The elevation of these scores (noticeably higher than Questions 24-26 on some basic functions and operations) is likely in part to students worrying about their ability to apply their knowledge in a new way, or to a question that they have never seen before. They may doubt that their knowledge extends past the basics and therefore feel more anxiety toward such questions. The remaining questions target particular concepts in mathematics. True to an earlier point that as students work with a concept more often that they become more comfortable and perhaps less anxious we indeed see that scores for Questions 24-26 all remain at or below a level 2 on the anxiety scale. By the time a student has entered university (particularly in a STEM field) basic operations of addition, subtraction, multiplication, and division have become second nature. Pairwise, we see a significant difference between Year 1 and Year $4+$ students only. Year 1 students may have more anxiety purely because they are still unsure of their capabilities in university as a whole. We see an increase in anxiety when we look at more complex functions such as logarithms and exponentials or trigonometric functions. While these functions are covered in the Ontario mathematics curriculum in high school (as well as in many other provinces and countries around the world) the fact that students have seen less of these concepts surely contributes to their level of anxiety here. Pairwise comparisons revealed that once again Year 1 students are more anxious than Year 4 and $4+$ students when it comes to logarithms and exponentials (indeed we see the numbers drop off in terms of average anxiety scores for upper year students), and for trigonometry, Year 1 students are found to be 
more anxious than all other years. Certainly, these more complex functions are widely used in the Engineering discipline. Entry level testing reveals that logarithms, exponentials and trigonometry are all topics that exhibit the most struggle by entry-level students (Levere \& Demers, 2017). University provides more time for students to use these functions and become comfortable. Indeed, we do see a decrease in time in anxiety scores in these categories, with Year 4+ falling in the "None at all" category for anxiety.

Looking at the proportion of HA students in the NA category we see a range of just under $5 \%$ of Year 4 student to just under 16\% of Year 1 students (again, not monotonically increasing by year). The only statistically significant pairwise comparison showed that there were a higher proportion of HA Year 1 students versus Year 4 students. For the LMA category, HA was classified as a student scoring a 4 or 5 on the anxiety scale in at least 3 of the 5 questions.

\subsection{Student Perception of Math Anxiety Over Time}

Question 6 of our survey asked students to identify their level of anxiety now relative to their previous year of study. Indeed, a significant difference in median scores between years of study was found with a p-value of $1.56 \times 10^{-13}$. Pairwise Mann-Whitney tests indicated that Year 1 students identified as significantly more anxious in their current year than in previous years. The results of this question do indicate that MA does level off (landing in the "a little" category, on average) after Year 1 studies. Similar explanations to earlier apply in this case, but certainly it is interesting to observe that student perception of anxiety indeed agrees with the trends found in this study.

\section{Conclusions and Future Work}

The results of this study reveal stronger feelings of MA (and a higher proportion of HA students) toward evaluation rather than numerical calculation or learning math. In fact, the only average anxiety scores that exceeded a neutral score (and often across all years) were questions related to major assessments, the anticipation of these assessments, or receiving grades. Very often differences in years of study revealed that Year 1 students exhibited higher levels of anxiety. As discussed, a host of reasons may explain this from transition to university, lack of confidence, motivation by grades, fear of failure, time management, and anticipation. While a gradual decrease in average anxiety scores was common in many questions, the amount of decrease was often not significant from year to year, by the end of a university degree, most Year 4+ (or even Year 4) students experience a decrease in feelings of anxiety across nearly all questions.

Earlier studies suggest that MA levels off around grade 10. The resoundingly low scores in learning and numerical anxiety in this study do lend truth to this claim, however, with regard to evaluation anxiety, it seems that MA is felt long into a student's university years (even among those that choose a STEM discipline). Further, even student's perception of anxiety over time suggests that indeed MA is still strong in Year 1 of university and that it tapers off thereafter. Perhaps one explanation for this is that the questions on the MARS questionnaire may be better suited to determining MA in younger students. For 
instance, when looking at the MARS questions regarding basic mathematical operations of addition, subtraction, multiplication, and division to a younger student just learning these concepts, it may be more likely that they experience MA in these areas, while a high school student (and certainly a university student) has had much more time to practice and perfect these operations, therefore, yielding lower MA scores on such a question. It is not that MA has decreased or leveled off necessarily, but rather that the mathematical concepts that induce MA change over time as students master the material and graduate to more complex mathematical concepts. Further, some of the MARS questions may not be specific to mathematics anxiety. The addition of questions specific to, for instance, testing in other disciplines when paired with questions on testing in math courses may provide further insight on whether we are uncovering math evaluation anxiety or just general evaluation anxiety. Perhaps an investigation into a progressive MARS questionnaire that accounts for knowledge over time as well as more attention to differences in anxiety across disciplines would shed more informative light on MA as a whole.

This study suggests that perhaps the current MARS scale is most effective at assessing MA in younger students studying in primary school rather than those studying at secondary or post-secondary levels. As older continue to struggle with MA, perhaps additional tools or adjustments to the current MARS questionnaire are necessary to get an accurate reading of MA across all ages. Efforts to alleviate MA should extend to Year 1 students and their transition to university. For instance, instructors should be informed and taught about the prevalence of MA and MEA, particularly in Year 1 students. They should readily address the concerns and challenges of MA with their students and provide coping techniques and strategies. Careful attention should be paid when developing assessments to ensure that the language used is clear and does not induce anxiety (for instance avoiding words like "abstract"). Ample time should be given for proctored assessments to allow students time to relax, perhaps make mistakes, and still feel that they are able to complete the assessment. These tactics can aid transitioning Year 1 students in finding ways to tackle their MA while feeling supported and giving them more interest and energy for learning. Perhaps earlier attention to MEA, even in secondary school, may help to desensitize students to MEA long-term. Perhaps further research into evaluation techniques and strategies that work to minimize student anxiety can also be explored. Finally, it would be interesting to attempt to isolate MEA from general test anxiety by addressing student reactions to a multitude of disciplines rather than mathematics alone to gain insight into why mathematics causes more anxiety than other disciplines.

\section{Limitations of Research}

While this research provides insight into testing for mathematics anxiety at the university level, certainly there are limitations to these conclusions. Most obviously, a longitudinal study may provide a more accurate depiction of how anxiety changes over time. In this study, the years of study being compared contained different groups of students. A future study could follow a cohort of the same students, tracking their responses to MA questions as they progressed 
through their degrees. The time at which the survey was conducted in this study may also impact student responses. Students that are just finishing major assessments or have them looming may be feeling more anxiety than normal which could impact their responses. Finally, this study was conducted on Engineering students at the University of Guelph. To gain a broader perspective, students in other disciplines and at other institutions should also be considered.

\section{Acknowledgments}

The authors would like to graciously acknowledge the efforts of the University of Guelph Research Ethics Board. This research was approved both for conducting the aforementioned survey as well as publication of results under certificate number 19-02-028.

\section{References}

Ahmed, W. (2018). Developmental trajectories of math anxiety during adolescence: Associations with STEM career choice. Journal of Adolescence, 67. doi:10.1016/j.adolescence.2018.06.010

Ahmed, W., van der Werf, G., Kuyper, H., \& Minnaert, A. (2013). Emotions, selfregulated learning, and achievement in mathematics: A growth curve analysis. Journal of Educational Psychology, 105(1), 150-161. doi:10.1037/a0030160

Alexander, L., \& Martray, C. (1989). The Development of an Abbreviated Version of the Mathematics Anxiety Rating Scale. Measurement and Evaluation in Counseling and Development, 22(3), 143-150. doi:10.1080/07481756.1989.12022923

Alpert, R., \& Haber, R. N. (1960). Anxiety in academic achievement situations. Journal of Abnormal and Social Psychology, 61, 207-215. doi:10.1037/h0045464

Ashcraft, M.H., \& Faust, M.W. (1994). Mathematics anxiety and mental arithmetic: an exploratory investigation. Cognition $\mathcal{E}$ Emotion, 8, 97-125. doi:10.1080/02699939408408931

Ashcraft, M.H., \& Krik, E.P. (2001). The relationships among working memory, math anxiety, and performance. Journal of Experimental Psychology: General, 130, $224-$ 237. doi:10.1037/0096-3445.130.2.224

Ashcraft, M.H., \& Moore, A.M. (2009). Mathematics anxiety and the affective drop in performance. Journal of Psychoeducational Assessment, 27, 197-205. doi:10.1177/0734282908330580

Beilock, S.L., Gunderson, E.A., Ramirez, G., \& Levine, S.C. (2010). Female teachers' math anxiety affects girls' math achievement. Proceedings of the National Academy of Sciences, 107(5), 1060-063. doi:10.1037/e634112013-097

Choe, K., Jenifer, J. B., Rozek, C. S., Berman, M., \& Beilock, S. L. (2019). Calculated Avoidance: Math Anxiety Predicts Math Avoidance in Effort-Based DecisionMaking. doi:10.31234/osf.io/afj37

Faust, M.W. (1992). Analysis of physiological reactivity in mathematics anxiety. Unpublished doctoral dissertation, Bowling Green State University, Ohio.

Fennema, E. (1989), The study of affect and mathematics: A proposed generic model for research. In D.B. McLeod \& V.M. Adams (Eds.), Affect and mathematical problem solving: A new perspective (pp.205-219). New York: Springer-Verlag. doi:10.1007/978-1-4612-3614-6_14

Grupe, D.W. \& Nitschke, J.B. (2013). Uncertainty and anticipation in anxiety: an integrated neurobiological and psychological perspective. Nature Reviews 
Neuroscience, 14(7), 488-501. Uncertainty and anticipation in anxiety: an integrated neurobiological and psychological perspective

Hembree, R. (1987). The effect of spatial disorders on arithmetic skills. In G. Deloche \& X. Seron (Eds.), Mathematical disabilities: A cognitive neuropsychological perspective, (pp. 121-135). Hillsdale, NJ: Erlbaum. doi:10.4324/9780429488542-6

Hopko, D.R., Mahadevan, R., Bare, R.L., \& Hunt, M.A. (2003) The Abbreviated Math Anxiety Scale (AMAS): Construction, validity, and reliability. Assessment, 10, 178-182. doi:10.1177/1073191103010002008

Immerwahr, J. (2011). The Case for Motivational Grading. Teaching Philosophy, 34(4), 335346. doi:10.5840/teachphil201134446

Jansen, B.R.J, Louwerse, J., Straatemeier, M., Van der Ven, S.H.G, Klinkenberg, S., \& Van der Maas, H.L.J. (2013). The influence of experiencing success in math on math anxiety, perceived math competence, and math performance. Learning and Individual Differences, 24, 190-197. doi:10.1016/j.lindif.2012.12.014

Levere, K.M. \& Demers, M. (2017). Effects of Warm-up Testing on Student Learning. International Journal of Learning, Teaching, and Educational Research, 16(4), 91-103.

Madjar, N., Zalsman, G., Weizman, A., Lev-Ran, S., \& Shoval, G. (2018). Predictors of developing mathematics anxiety among middle-school students: A 2-year prospective study. International Journal of Psychology, 53(6), 426-432. doi:10.1002/ijop.12403

McGhie, V. (2017). Entering university studies: identifying enabling factors for a successful transition from school to university. Higher Education, 73(3), 407-422. doi:10.1007/s10734-016-0100-2

McKeachie, Wilbert J. (1999). Teaching Tips: Strategies, Research, and Theory for College and University Teachers, 10th ed. Boston: Houghton Mifflin. doi:10.2307/328598

Nathan, R. (2005). My Freshman Year: What a Professor Learned by Becoming a Freshman (Ithaca, N.Y.: Cornell University Press).

O'Connor, J.P., Lorr, M., \& Stafford, J.W. (1956). Some patterns of Manifest Anxiety. Journal of Clinical Psychology, 12(2), 160-163. doi:10.1002/10974679(195604)12:2<160::aid-jclp2270120212>3.0.co;2-k

Plake, B.S., \& Parker, C.S. (1982). The Development and Validation of a Revised Version of the Mathematics Anxiety Rating Scale. Educational and Psychological Measurement, 42(2), 551-557. doi:10.1177/001316448204200218

Richardson, F., \& Suinn, R. (1972). The Mathematics Anxiety Rating Scale: Psychometric Data. Journal of Counseling Psychology, 19, 551-554. doi:10.1037/h0033456

Rounds, J. B., \& Hendel, D. D. (1980). Measurement and dimensionality of mathematics anxiety. Journal of Counseling Psychology, 27(2), 138-149. doi:10.1037/00220167.27.2.138

Taylor, J.A., (1953), A personality scale of manifest anxiety. The Journal of Abnormal and Social Psychology, 45(4), 265-272. doi:10.1037/14156-007

Turner, J.C., Midgley, C., Meyer, D.K., Ghenn, M., Anderman, E.M.m \& Kang, Y. (2002). The classroom environment and students' reports of avoidance strategies in mathematics: A multi method study. Journal of Educational Psychology, 94, 88-106. doi:10.1037/0022-0663.94.1.88

Wigfield, A., \& Eccles, J.S. (1989). Anxiety and worries about math and English before and after the junior high transition. Paper presented at the annual meeting of the American educational research association, San Francisco, CA. 


\section{Appendix}

The following questions comprised the survey presented to students using Qualtrics survey software.

To open the survey, the user was directed to a list of procedures and terms of consent. They were then asked to select one of the following options:

I consent, begin the study

I do not consent, I do not wish to participate in the study.

If the latter was chosen, the user was thanked and exited from the survey. Those consenting were then asked the following 29 questions, with option to answer or not answer as many questions as they wished.

Q1: Which year of your undergraduate degree are you currently enrolled?
○ 1
○ 2
$\circ 3$
$\circ 4$
○ $4+$

Q2: Which Engineering degree program are you currently enrolled in the University of Guelph?
○ Biological
○ Biomedical
- Computer
○ Systems \&
Computing
- Environmental $\bigcirc$ Mechanical
○ Undeclared
- Water Resources

For each of the remaining questions, respondents were asked to indicate their answer on the following scale
- None at all
$\circ$ A little
- A moderate
○ A lot
- A great
deal
amount

Q3: What would you rate the level of math that this course requires from previous courses/knowledge?

Q4: What would you rate the level of math that this course introduces?

Q5: Do you feel that the knowledge obtained in your undergraduate degree so far has provided you with sufficient math skills for your current career path?

Q6: Rate your level of math anxiety last year, relative to now.

For questions 8 through 29, please indicate the level of your anxiety in the following situations:

Q7: Being given difficult problems on a homework assignment that is due next class.

Q8: Thinking about an upcoming math test one day before.

Q9: Taking a quiz in a math course. 
Q10: Receiving your final math grade via Web Advisor.

Q11: Being given an in class "pop" quiz (ex. through iclicker).

Q12: Waiting to get a math test/midterm returned in which you expected to do well.

Q13: Waiting to get a math test/midterm returned in which you do not expect that you did well.

Q14: Taking an examination (final) in a math course.

Q15: Working on an abstract math problem.

(For example, if $x=$ outstanding bills and $y=$ total income; calculate how much you have left for recreational expenditures).

Q16: Picking up a math textbook to begin working on a homework assignment.

Q17: Opening a math or statistics book and seeing a full page of problems.

Q18: Walking on campus and thinking about a math course.

Q19: Reading and interpreting charts or graphs.

Q20: Having to use tables in the back of your book.

Q21: Listening to another student explain a math formula or concept when working on homework problems.

Q22: Listening to another student explain a math formula or concept right before a test.

Q23: Waiting outside the classroom right before a math or statistics test is about to begin.

Q24: $\quad$ Being given a set of addition/subtraction/multiplication/division problems to solve on paper (showing your work).

Q25: Being given a set of logarithmic/exponential function problems to solve on paper (showing your work).

Q26: Being given a set of trigonometric problems to solve on paper (showing your work).

Q27: Being asked a question that is an extension of a problem done in class (showing your work).

Q28: Being asked to use material taught in a previous course to complete a problem in a different course.

Q29: Going to see a professor in office hours to ask for help. 